\title{
Retrograde Traffic from the Golgi to the Endoplasmic Reticulum
}

\author{
Anne Spang \\ University of Basel, Biozentrum, Growth \& Development, Klingelbergstrasse 70, 4056 Basel, Switzerland \\ Correspondence: anne.spang@unibas.ch
}

Proteins to be secreted are transported from the endoplasmic reticulum (ER) to the Golgi apparatus. The transport of these proteins requires the localization and activity of proteins that create ER exit sites, coat proteins to collect cargo and to reshape the membrane into a transport container, and address labels_-SNARE proteins - to target the vesicles specifically to the Golgi apparatus. In addition some proteins may need export chaperones or export receptors to enable their exit into transport vesicles. ER export factors, SNAREs, and misfolded Golgi-resident proteins must all be retrieved from the Golgi to the ER again. This retrieval is also part of the organellar homeostasis pathway essential to maintaining the identity of the ER and of the Golgi apparatus. In this review, I will discuss the different processes in retrograde transport from the Golgi to the ER and highlight the mechanistic insights we have obtained in the last couple of years.

$\mathrm{P}_{\mathrm{b}}^{\mathrm{r}}$ roteins that are exposed at the plasma membrane or populate a membrane-bounded organelle are synthesized into the endoplasmic reticulum (ER). In the ER, the folding of these proteins takes place and posttranslational modifications such as $\mathrm{N}$-glycosylation and disulfide bridge formation occur. Upon adopting a suitable, often correct, conformation, proteins destined to locations beyond the ER are concentrated at so-called ER exit sites (ERES) and incorporated into nascent COPII-coated vesicles. These COPII vesicles eventually bud off the ER membrane and are transported to the Golgi (in yeast, Drosophila, and C. elegans) or the ER-Golgi intermediate compartment (in mammalian cells) (Schweizer et al. 1990; Kondylis and Rabouille 2003; Spang 2009; Witte et al. 2011).
It is assumed that the vesicle coat is at least partially destabilized through the hydrolysis of GTP by the small GTPase Sar 1 (Oka and Nakano 1994; Springer et al. 1999). However, some of the destabilized coat components have to stay on the vesicle until it has reached the Golgi apparatus because coat components participate in the recognition and the tethering process (Barlowe 1997; Cai et al. 2007; Lord et al. 2011; Zong et al. 2012). Subsequently, SNARE proteins on the vesicles ( $v$-SNAREs) zipper up with cognate SNAREs on the Golgi (target SNAREs, tSNAREs) to drive membrane fusion (Hay et al. 1998; Cao and Barlowe 2000; Parlati et al. 2002). The content of the ER-derived COPII vesicles is thereby released into the lumen of the ciscisterna of the Golgi apparatus. Most proteins will continue their journey through the Golgi

Editors: Susan Ferro-Novick, Tom A. Rapoport, and Randy Schekman

Additional Perspectives on The Endoplasmic Reticulum available at www.cshperspectives.org

Copyright (C) 2013 Cold Spring Harbor Laboratory Press; all rights reserved; doi: 10.1101/cshperspect.a013391

Cite this article as Cold Spring Harb Perspect Biol 2013;5:a013391 
apparatus and encounter further modifications such as extension of the glycosylation tree or lipidation. However, some proteins, especially those involved in the fusion process, i.e., the vSNAREs or proteins that act as export factors of the ER, such as Vma21, which is essential for export of the correctly folded and assembled $\mathrm{V} 0$ sector of the V-ATPase, need to be recycled back to the ER for another round of transport (Ballensiefen et al. 1998; Malkus et al. 2004). Moreover, cis-Golgi proteins are returned to the ER for quality/functional control (Todorow et al. 2000; Sato et al. 2004; Valkova et al. 2011). Finally, some ER-resident proteins, such as the ER Hsp70 chaperone BiP/Kar2, can escape the $\mathrm{ER}$, but are captured at the cis-Golgi by the H/ KDEL receptor Erd2 and returned to the ER (Lewis et al. 1990; Semenza et al. 1990; Aoe et al. 1997).

Unfortunately, the retrograde transport route is also hijacked by toxins. For example, endocytosed cholera toxin subunit A contains a KDEL sequence and can thereby exploit the system to access the ER (Majoul et al. 1996, 1998). From there, it is retro-translocated into the cytoplasm where it can exert its detrimental function.

\section{VESICLE FORMATION AT THE GOLGI APPARATUS}

\section{COPI Vesicles}

Most transport vesicle formation appears to follow an evolutionarily and structurally conserved scheme. First, a small GTPase of the Arf1/Sar1 family is recruited to the membrane by the action of a guanine nucleotide exchange factor (GEF). Then a layer of the coat binds to the activated small GTPase and recruits cargo at the same time. If there is enough cargo available, the GTPase.coat.cargo complex is stabilized. Interestingly, this first inner layer of the coat also contains a GTPase activating protein (GAP), which thus becomes an intrinsic part of the coat complex. However, the arrangement in this prebudding complex is such that the GAP cannot efficiently stimulate the GTPase activity of the small GTPase. Next, a second layer of the coat is recruited with the ability to deform the membrane of the donor compartment. This outer coat layer also plays an important role in determining the size of the transport vesicle. The binding of the second layer/outer shell drives polymerization of the coat, which leads to the deformation of the membrane. Finally, the transport vesicle is formed and fission from the donor compartment needs to occur. In the case of clathrin-coated vesicles dynamin, a GTPase with the ability to polymerize and form a tight constriction, binds to the base of the vesicle and drives scission (van der Bliek et al. 1993; Hinshaw and Schmid 1995; Takei et al. 1995). In all other vesicle budding scenarios, the mechanistic basis for severing the vesicle from the donor membrane is much less clear, although a direct role of the Arf1/Sar1 GTPases has been proposed because each of them can oligomerize and cause tubulation of liposomes in vitro (Bielli et al. 2005; Lee et al. 2005a; Beck et al. 2008, 2011).

The players at the cis-Golgi involved in COPI vesicle formation follow the general scheme outlined above, beginning with the GEF at the cisGolgi, GBF1 (Gea1/2 in yeast) (Peyroche et al. 1996, 2001; Spang et al. 2001; Zhao et al. 2006). How the GEF is itself recruited is not entirely clear. One determinant appears to be the phosphoinositide PI4P (Dumaresq-Doiron et al. 2010). However, lipid binding cannot account for the specific recruitment of the GEF to the cis face of the Golgi. How the temporal and spatial control of GBF1 Golgi localization is achieved would be an important piece of information, as the localization of the GEF determines where the small GTPase Arf1 is activated. Upon activation, Arf1 is recruited to the Golgi, where it initiates the binding of the heptameric coat complex, coatomer. This complex can be divided up into two layers: a tetrameric subcomplex resembling adaptor complexes of the clathrin coat and a cage-like trimeric subcomplex possibly containing the membrane-deforming ability of the complex (Yu et al. 2012). Two Arf1 proteins interact with the tetrameric subcomplex to initiate membrane recruitment of coatomer (Yu et al. 2012). In the case of COPI vesicles, the first and second layers of the coat are 
thought to be recruited simultaneously. This is because the coatomer complex exists as a preassembled heptameric complex in the cytoplasm (Waters et al. 1991; Hosobuchi et al. 1992; Robinson and Kreis 1992; Hara-Kuge et al. 1994). Furthermore, the purified heptameric complex, together with activated Arf1 and guanine nucleotides, is sufficient to generate COPI-coated vesicles from synthetic liposomes (Spang et al. 1998). However, different types of the coatomer complexes exist, one of which appears to act at the level of endosomes (Whitney et al. 1995; Aniento et al. 1996; Gu et al. 1997). Here, we will concentrate on the coatomer complex at the cis-Golgi.

The coatomer complex by itself is unable to stimulate GTP hydrolysis by Arf1; ArfGAPs have to be included and are intrinsic parts of the coat. Although in yeast two different ArfGAPs, Gcs1 and Glo3, have partially overlapping functions in COPI vesicle formation and can substitute for each other (Poon et al. 1999), their mammalian counterparts, ArfGAP1 and ArfGAP2/3, may have very distinct functions (Frigerio et al. 2007; Weimer et al. 2008; Shiba et al. 2010). Yet, Gcs1 and ArfGAP1 contain socalled ALPS motifs that are able to sense membrane curvature, whereas Glo3 interacts with cargo, SNARE proteins, and coatomer through its BoCCS (binding of coatomer, cargo, and SNAREs) domain (Bigay et al. 2005; Schindler et al. 2009). Glo3, but not Gcs1, is found on COPI vesicles (Lewis et al. 2004), whereas in mammals ArfGAP1 appears to be a component of COPI vesicles (Yang et al. 2002). These data were recently challenged because the analysis of ArfGAP2 and ArfGAP3 revealed a more prominent role of these GAPs than of ArfGAP1 for coatomer polymerization and Golgi integrity (Kartberg et al. 2010). It is likely that there are common and distinct roles for Glo3 (ArfGAP2/ 3 ) and Gcs1 (ArfGAP1) in the life cycle of a COPI vesicle. The common role would be the involvement of cargo packaging into nascent vesicles (Lanoix et al. 2001; Rein et al. 2002; Schindler et al. 2009). The distinct roles can be separated temporally and functionally. Gcs1 (ArfGAP1), with its ability to sense curvature, could act as part of the pinchase that would liberate the nascent vesicle from the donor membrane, and hence act early in vesicle biogenesis. In contrast, Glo3 (ArfGAP2/3) would stabilize the coat on the nascent vesicle and finally would initiate uncoating by stimulating GTP hydrolysis on Arf1; this latter function being probably required late in the vesicle's lifetime.

Before it can fuse with a target compartment, a vesicle's coat must be at least partially disassembled or destabilized. This led us to ask when uncoating would occur. Multiple scenarios have been discussed for COPI and COPII vesicles. It is assumed, as discussed above, that generation and consumption of COPI and COPII vesicles follow a very similar mechanism. Therefore, I will use the following findings from either COPI or COPII vesicles to illustrate our current understanding of uncoating. Initially, it was believed that uncoating occurs just before the fusion event; the coat might therefore play a role in targeting a vesicle to the correct destination. The basis for this model was the finding that in the presence of either the nonhydrolysable GTP analog GTP- $\gamma-S$, or the Arf1Q71L mutant, which is defective in hydrolysis and therefore predominantly bound to GTP, COPIcoated vesicles accumulate (Tanigawa et al. 1993). This model was replaced by one in which GTP hydrolysis occurs early in the vesicle budding process. The "early uncoating" model is based on in vitro data that Sar1 GTP hydrolysis is 50-fold enhanced by the presence of the ER-localized GEF Sec12 and the COPII coat component and Sar1 GAP Sec23 (Barlowe and Schekman 1993; Schekman and Orci 1996; Springer et al. 1999). Moreover, coatomer binding to ArfGAP stimulates GTP hydrolysis by Arf1 1000-fold (Goldberg 1999). This early hydrolysis would increase cargo incorporation into COPI vesicles (Lanoix et al. 1999, 2001; Elsner et al. 2003) and would lead to destabilization of the coat (Bigay et al. 2003), so that in principle, uncoating at the tip of the nascent vesicle could occur while the base of the vesicle is still connected to the donor compartment (Springer et al. 1999). This model went out of fashion with the identification of COPII cages (Antonny et al. 2003; Fath et al. 2007). These 
cages consist of the first and second layer of the coat and are devoid of the small GTPase Sar1, indicating that neither the presence of Sar1 nor the nature of its bound nucleotide is obligately linked to coat stability. Vesicles with this "metastable coat" might diffuse (or be actively transported) to the target organelle, where uncoating would then be initiated. Whether or not this scenario is accurate for COPII vesicles, its relevance to COPI coated vesicles en route from the Golgi to the ER remains unclear because no COPI cages have been reported to date, although their existence has been inferred from the crystallization of the $\alpha \beta^{\prime}$-COP core (Lee and Goldberg 2010). However, in a recent study the way coatomer assembles onto membranes has been challenged (Faini et al. 2012). Thus, the temporal regulation of coat destabilization and its relationship to Arf1 GTP hydrolysis remain unresolved.

One possibility has received surprisingly little attention: coat stability could be regulated by reversible posttranslational modifications such as phosphorylation and ubiquitylation. Indeed, Gcs1 and Glo3 are phosphoproteins (Bodenmiller et al. 2007), with the Glo3 regulatory motif (Yahara et al. 2006; Schindler et al. 2009) phosphorylated at multiple sites (Bodenmiller et al. 2007). Because the Glo3 regulatory motif regulates the activity of the Glo3 GAP and BoCCS domains, differential phosphorylation could act as a trigger of Arf1 GTP hydrolysis and subsequent coat depolymerization. Phosphorylation event could potentially be linked to the initial tethering of the COPI vesicle with the ER. In addition, $\beta^{\prime} \mathrm{COP}$ appears to be deubiquitylated by the Ubp3·Bre5 complex to maintain the heptameric coatomer complex (Cohen et al. 2003). Removal of at least some coatomer complexes from vesicles appears to happen late in the life cycle of a transport vesicle as the ER tethering complex can recognize coatomer (Andag et al. 2001; Vanrheenen et al. 2001), and Sec18/NSF can displace Arf1 from SNAREs in vitro (Schindler and Spang 2007).

Although COPI-coated vesicles can be formed from liposomes in the absence of cargo or cargo-tails (Spang et al. 1998), cargo unquestionably plays a pivotal role in the generation of transport carriers in vitro and in vivo (Bremser et al. 1999). The best-studied cargoes are the proteins of the p24 family, which themselves are involved in the export of other proteins at the ER and which cycle between the ER and the Golgi (Fiedler et al. 1996; Bethune et al. 2006; Aguilera-Romero et al. 2008); as such, both they and SNARE proteins are found in COPI and in COPII vesicles (Springer and Schekman 1998; Rein et al. 2002; Honda et al. 2005; Lee et al. 2005b; Schindler et al. 2009). Cargo interacts either directly or indirectly, via cargo receptors or chaperones, with structural components of the coat. Such cargo-coat interactions stabilize the coat after GTP hydrolysis commences. Moreover, at least from studies in the COPII system, it is also apparent that the size and the availability of cargoes regulate the size (Stagg et al. 2008; Copic et al. 2012; Jin et al. 2012) and the number (Farhan et al. 2008) of transport vesicles, respectively. To maintain ER/Golgi homeostasis, COPI vesicles formation might be regulated in a similar manner.

\section{COPI-Independent Transport Carriers}

Besides COPI-dependent transport from the Golgi to the ER, an independent pathway was identified in which neither Arf1 nor coatomer play a role, and for which the vesicle coat remains unknown. Through a slow transport pathway, Shiga toxin lacking a KDEL retrieval sequence and the Golgi-resident galactosyltransferase can reach the ER in a Rab6A-dependent manner (Girod et al. 1999). The further analysis of the pathway is hampered by the fact that Rab6 is also involved in COPI- and clathrin-dependent trafficking steps at the Golgi (Storrie et al. 2012), demanding careful dissection of the different roles of Rab6A and illustrating the need to identify Rab6A effectors specific for an individual pathway. To complicate the issue, Rab6-COPI-independent (Chen et al. 2003) and Rab6-COPI-dependent pathways have also been reported (Smith et al. 2009) that appear to function in parallel with the classical COPI retrograde Golgi-ER pathway. The biological function of these pathways remains elusive but one possibility would be that they 
are part of a stress response, especially because each of them has been characterized primarily based on a specific toxin they transport. These toxins may create membrane stress, interfere with protein structure in the Golgi by binding glycosphingolipids and glycans (Gallegos et al. 2012), or interfere with glycolipid biosynthesis. The cell might respond to such stress with a special retrieval mechanism to the ER. However, these are only speculations and further research is necessary to provide mechanistic insights into COPI-independent transport from the Golgi to the ER. The remainder of this review will focus on COPI-dependent retrograde vesicles and their fusion with the ER.

\section{TARGETING AND FUSION OF VESICLES WITH THE ER}

A COPI vesicle is formed at the face of the cisGolgi and either diffuses (in yeast) or is actively transported on microtubules (in mammalian cells), most likely by dynein (Chen et al. 2005), toward the endoplasmic reticulum. Either in the cytoplasm or on the ER membrane, the COPI vesicle encounters the tethering complex DSL1, also referred to as the syntaxin 18 complex. The DSL1 complex is a member of the so-called CATCHR (complexes associated with tethering containing helical rods) tethers and is the only CATCHR for which a complete structural model has been reported (Ren et al. 2009; Tripathi et al. 2009; Spang 2012). The definition of a tethering complex is somewhat ambiguous but generally signifies that it is the first component to "touch" the transport vesicle, initiating an ordered series of events culminating in the fusion of the vesicle with the acceptor compartment-in this case, the ER. Also ill-defined is the part played by the Rab GTPases that are clearly involved but whose precise role remains elusive. The Rab GTPase involved in retrograde transport to the ER is Rab1/Ypt1 (Kamena et al. 2008). Most tethering complexes function as Rab effectors and are recruited to membranes by the activated Rab. In general, it is assumed that the tether, anchored via the activated Rab GTPase to the target membrane, makes the first contact with the vesicle by recognizing its coat. Two of the three subunits comprising the DSL1 complex are capable of binding coatomer (Zink et al. 2009; Diefenbacher et al. 2011) and may facilitate uncoating (Zink et al. 2009). This would expose the v-SNAREs to interact with the $\mathrm{t}$ SNAREs on the target membrane, with the subsequent formation of a membrane-bridging four-helix bundle. Of the four helices, three are contributed by three different t-SNAREs on the ER membrane whereas one is contributed by the v-SNARE on the uncoated (or partially coated) vesicle. This is in marked distinction to COPII vesicle traffic, in which one Golgi tSNARE engages three vesicle t-SNAREs during the fusion process (Spang and Schekman 1998; Cao and Barlowe 2000; Parlati et al. 2002). These different requirements may also play a role in the directionality of the respective transport processes.

Several years ago, before the identificytion of the DSL1 complex, we found that a specific mutation, tip20-8, could override the safeguard of vectorial transport between the ER and the Golgi by allowing ER-derived COPII vesicles to fuse back with the ER, a process which is normally prohibited in the cell (Kamena and Spang 2004). The recent discovery that the DSL1 complex promotes and accelerates SNARE complex formation in vitro (Ren et al. 2009; Diefenbacher et al. 2011; Meiringer et al. 2011) provides a possible explanation for this observation. The DSL1 complex may selectively facilitate the formation of correct SNARE complexes by acting as a chaperone. Indeed, this mechanism may not be limited to COPI vesicle fusion at the ER. Another tethering complex, HOPS, was recently shown to restrict the formation of cis-SNARE complexes and thereby promote trans-SNARE complex formation (Alpadi et al. 2012). In a trans-SNARE complex, v- and tSNAREs are on opposing membranes. After the vesicle has fused with the ER, the resulting cisSNARE complexes ( $\mathrm{v}$ - and $\mathrm{t}-\mathrm{SNAREs}$ are in the same membrane, interacting in cis) are disassembled by the action of Sec18/NSF in conjunction with Sec17/ $\alpha$-SNAP, and the v-SNAREs can diffuse to an ER exit site to be incorporated into COPII vesicles (Spang and Schekman 1998; Spang 2008). 


\section{A. Spang}

\section{GOLGI-ER TRANSPORT OVER EXTREMELY SHORT DISTANCES}

In a number of cells and organisms, the cis-Golgi is juxtaposed to ER exit sites where COPII vesicles are formed. This is not restricted to singlecelled organisms such as yeast, but has also been observed in C. elegans and D. melanogaster (Rossanese et al. 1999; Kondylis and Rabouille 2003; Connerly et al. 2005; Witte et al. 2011). The distance between the ER and the cis-Golgi in these cases is $100-150 \mathrm{~nm}$. Because of this close proximity, this region is also referred to as the tER-Golgi unit (Levi et al. 2010; Kondylis et al. 2011). Consideration of the size of a coated COPI or COPII vesicle (around $70 \mathrm{~nm}$ ) casts some of the above considerations into a different light. How important is it, really, to time GTP hydrolysis and coat destabilization in such a setting? The budded transport vesicle will more-or-less immediately bump into the target compartment. Considering this, it appears less surprising that parts of the COPII coat interact with proteins on the Golgi, or that COPI vesicles have binding partners on the ER.

Clearly the cytoskeleton and motor activity are dispensable for vesicle transport under these circumstances. How critical is the tethering of vesicles at the cis-Golgi and the ER membrane? Mutations in tethering factors have detrimental effects, but perhaps it is not so much the tethering function that is needed but rather their positive effect on trans-SNARE complex formation. Juxtaposed ER exit sites (ERES)/Golgi

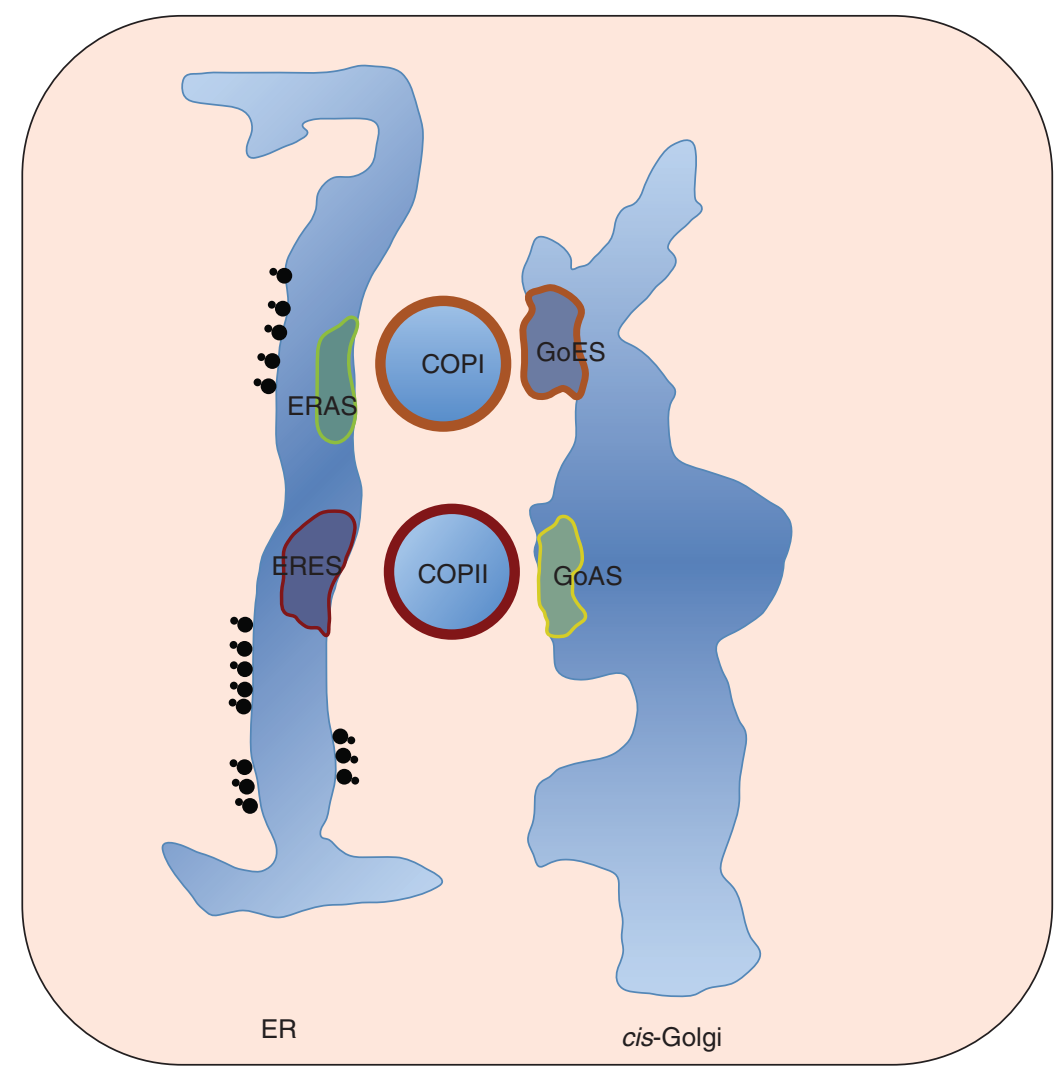

Figure 1. Schematic depiction of how cargo shuttles between the ER and Golgi. COPII vesicles are formed at ERES and fuse at GoAS, whereas COPI vesicles are generated at GoES and are consumed at ERAS. The arrival sites contain t-SNAREs and tethering factors, whereas the exit sites are enriched in GEFs for the small GTPases, coat components, and v-SNAREs/cargo. 
Retrograde Traffic from the Golgi to the ER

arrival sites (GoAS) could be created to build the landing platform for COPII vesicles, containing the cis-Golgi t-SNARE, Sed5/syntaxin5. Likewise, the Golgi exit sites (GoES) will be in very close proximity to ER arrival sites (ERAS) that will contain the ER t-SNAREs Ufe1/syntaxin18, Sec20 and Use1 as well as the DSL1 tethering complex (Fig. 1). Moreover, because these ER-Golgi transitional units are not very large, the GoAS and GoES as well as ERAS and ERES should also be in relatively close proximity, allowing communication and exchange of general transport factors, perhaps in particular v-SNARE proteins. After fusion of a COPI vesicle at the ERAS, the cis-SNARE complex would be disassembled by Sec18/NSF and the v-SNARE could be handed over to the ERES for another round of exit. This spatial organization might allow for extremely efficient transport by limiting the free diffusion of transport factors and regulators away from sites where they are required and hence solve the problem in generating exit sites randomly or de novo.

\section{CONCLUSIONS}

The last ten to fifteen years has increased our understanding of intracellular traffic in general and Golgi-ER retrograde transport in particular. However, many questions still remain. For example: how is lipid and protein homeostasis between the ER and Golgi sensed and regulated? It is conceivable that the availability of SNAREs or other transport factors would be monitored to maintain organelle identity as well as efficient transport, and how would this work with lipids? Is the timing of uncoating of transport vesicles traveling between ER and Golgi more of a philosophical than mechanistically relevant question, given the very short distance between ER and Golgi/ERGIC? Perhaps this could explain why no specialized uncoating factors, as in case for clathrin-coated vesicles, have been identified. Both COPI- and clathrin-coated vesicles require the small GTPase Arf1 for their formation, so why do only clathrin-coated vesicles need dynamin for fission and release? Many more questions remain to be answered in the future.

\section{ACKNOWLEDGMENTS}

The work on the early secretory pathway in the Spang lab is funded by the Swiss National Science Foundation, EMBO, and the University of Basel. Fred Hughson is acknowledged for critical comments on the manuscript.

\section{REFERENCES}

Aguilera-Romero A, Kaminska J, Spang A, Riezman H, Muniz M. 2008. The yeast p24 complex is required for the formation of COPI retrograde transport vesicles from the Golgi apparatus. J Cell Biol 180: 713-720.

Alpadi K, Kulkarni A, Comte V, Reinhardt M, Schmidt A, Namjoshi S, Mayer A, Peters C. 2012. Sequential analysis of trans-SNARE formation in intracellular membrane fusion. PLoS Biol 10: e1001243.

Andag U, Neumann T, Schmitt HD. 2001. The coatomerinteracting protein Dsllp is required for Golgi-to-endoplasmic reticulum retrieval in yeast. J Biol Chem 276: 39150-39160.

Aniento F, Gu F, Parton RG, Gruenberg J. 1996. An endosomal beta COP is involved in the $\mathrm{pH}$-dependent formation of transport vesicles destined for late endosomes. J Cell Biol 133: 29-41.

Antonny B, Gounon P, Schekman R, Orci L. 2003. Selfassembly of minimal COPII cages. EMBO Rep 4: 419424.

Aoe T, Cukierman E, Lee A, Cassel D, Peters PJ, Hsu VW. 1997. The KDEL receptor, ERD2, regulates intracellular traffic by recruiting a GTPase-activating protein for ARF1. EMBO J 16: 7305-7316.

Ballensiefen W, Ossipov D, Schmitt HD. 1998. Recycling of the yeast v-SNARE Sec22p involves COPI-proteins and the ER transmembrane proteins Ufe1p and Sec20p. J Cell Sci 111: 1507-1520.

Barlowe C. 1997. Coupled ER to Golgi transport reconstituted with purified cytosolic proteins. J Cell Biol 139: 1097-1108.

Barlowe C, Schekman R. 1993. SEC12 encodes a guaninenucleotide-exchange factor essential for transport vesicle budding from the ER. Nature 365: 347-349.

Beck R, Sun Z, Adolf F, Rutz C, Bassler J, Wild K, Sinning I, Hurt E, Brugger B, Bethune J, et al. 2008. Membrane curvature induced by Arf1-GTP is essential for vesicle formation. Proc Natl Acad Sci 105: 11731-11736.

Beck R, Prinz S, Diestelkotter-Bachert P, Rohling S, Adolf F, Hoehner K, Welsch S, Ronchi P, Brugger B, Briggs JA, et al. 2011. Coatomer and dimeric ADP ribosylation factor 1 promote distinct steps in membrane scission. J Cell Biol 194: $765-777$.

Bethune J, Kol M, Hoffmann J, Reckmann I, Brugger B, Wieland F. 2006. Coatomer, the coat protein of COPI transport vesicles, discriminates endoplasmic reticulum residents from p24 proteins. Mol Cell Biol 26: 8011-8021.

Bielli A, Haney CJ, Gabreski G, Watkins SC, Bannykh SI, Aridor M. 2005. Regulation of Sar1 NH2 terminus by GTP binding and hydrolysis promotes membrane 
deformation to control COPII vesicle fission. J Cell Biol 171: 919-924.

Bigay J, Gounon P, Robineau S, Antonny B. 2003. Lipid packing sensed by ArfGAP1 couples COPI coat disassembly to membrane bilayer curvature. Nature 426: 563-566.

Bigay J, Casella JF, Drin G, Mesmin B, Antonny B. 2005 ArfGAP1 responds to membrane curvature through the folding of a lipid packing sensor motif. $E M B O J$ 24: 2244-2253.

Bodenmiller B, Malmstrom J, Gerrits B, Campbell D, Lam H, Schmidt A, Rinner O, Mueller LN, Shannon PT, Pedrioli PG, et al. 2007. PhosphoPep-a phosphoproteome resource for systems biology research in Drosophila Kc167 cells. Mol Syst Biol 3: 139.

Bremser M, Nickel W, Schweikert M, Ravazzola M, Amherdt M, Hughes CA, Sollner TH, Rothman JE, Wieland FT. 1999. Coupling of coat assembly and vesicle budding to packaging of putative cargo receptors. Cell 96: 495-506.

Cai H, Yu S, Menon S, Cai Y, Lazarova D, Fu C, Reinisch K, Hay JC, Ferro-Novick S. 2007. TRAPPI tethers COPII vesicles by binding the coat subunit Sec23. Nature 445: 941-944.

Cao X, Barlowe C. 2000. Asymmetric requirements for a Rab GTPase and SNARE proteins in fusion of COPII vesicles with acceptor membranes. J Cell Biol 149: 55-66.

Chen A, AbuJarour RJ, Draper RK. 2003. Evidence that the transport of ricin to the cytoplasm is independent of both Rab6A and COPI. J Cell Sci 116: 3503-3510.

Chen JL, Fucini RV, Lacomis L, Erdjument-Bromage H, Tempst P, Stamnes M. 2005. Coatomer-bound Cdc42 regulates dynein recruitment to COPI vesicles. $J$ Cell Biol 169: 383-389.

Cohen M, Stutz F, Dargemont C. 2003. Deubiquitination, a new player in Golgi to endoplasmic reticulum retrograde transport. J Biol Chem 278: 51989-51992.

Connerly PL, Esaki M, Montegna EA, Strongin DE, Levi S, Soderholm J, Glick BS. 2005. Sec16 is a determinant of transitional ER organization. Curr Biol 15: 1439-1447.

Copic A, Latham CF, Horlbeck MA, D’Arcangelo JG, Miller EA. 2012. ER cargo properties specify a requirement for COPII coat rigidity mediated by Sec13p. Science 335: 1359-1362.

Diefenbacher M, Thorsteinsdottir H, Spang A. 2011. The Dsll tethering complex actively participates in soluble NSF ( $N$-ethylmaleimide-sensitive factor) attachment protein receptor (SNARE) complex assembly at the endoplasmic reticulum in Saccharomyces cerevisiae. J Biol Chem 286: 25027-25038.

Dumaresq-Doiron K, Savard MF, Akam S, Costantino S, Lefrancois S. 2010. The phosphatidylinositol 4-kinase PI4KIIIalpha is required for the recruitment of GBF1 to Golgi membranes. J Cell Sci 123: 2273-2280.

Elsner M, Hashimoto H, Simpson JC, Cassel D, Nilsson T, Weiss M. 2003. Spatiotemporal dynamics of the COPI vesicle machinery. EMBO Rep 4: 1000-1004.

Faini M, Prinz S, Beck R, Schorb M, Riches JD, Bacia K, Brugger B, Wieland FT, Briggs JA. 2012. The structures of COPI-coated vesicles reveal alternate coatomer conformations and interactions. Science 336: 1451-1454.
Farhan H, Weiss M, Tani K, Kaufman RJ, Hauri HP. 2008. Adaptation of endoplasmic reticulum exit sites to acute and chronic increases in cargo load. EMBO J 27: $2043-$ 2054.

Fath S, Mancias JD, Bi X, Goldberg J. 2007. Structure and organization of coat proteins in the COPII cage. Cell 129: 1325-1336.

Fiedler K, Veit M, Stamnes MA, Rothman JE. 1996. Bimodal interaction of coatomer with the p24 family of putative cargo receptors. Science 273: 1396-1399.

Frigerio G, Grimsey N, Dale M, Majoul I, Duden R. 2007. Two human ARFGAPs associated with COP-I-coated vesicles. Traffic 8: 1644-1655.

Gallegos KM, Conrady DG, Karve SS, Gunasekera TS, Herr AB, Weiss AA. 2012. Shiga toxin binding to glycolipids and glycans. PLoS ONE 7: e30368.

Girod A, Storrie B, Simpson JC, Johannes L, Goud B, Roberts LM, Lord JM, Nilsson T, Pepperkok R. 1999. Evidence for a COP-I-independent transport route from the Golgi complex to the endoplasmic reticulum. Nat Cell Biol 1: 423-430.

Goldberg J. 1999. Structural and functional analysis of the ARF1-ARFGAP complex reveals a role for coatomer in GTP hydrolysis. Cell 96: 893-902.

Gu F, Aniento F, Parton RG, Gruenberg J. 1997. Functional dissection of COP-I subunits in the biogenesis of multivesicular endosomes. J Cell Biol 139: 1183-1195.

Hara-Kuge S, Kuge O, Orci L, Amherdt M, Ravazzola M, Wieland FT, Rothman JE. 1994. En bloc incorporation of coatomer subunits during the assembly of COP-coated vesicles. J Cell Biol 124: 883-892.

Hay JC, Klumperman J, Oorschot V, Steegmaier M, Kuo CS, Scheller RH. 1998. Localization, dynamics, and protein interactions reveal distinct roles for ER and Golgi SNAREs. J Cell B 141: 1489-1502.

Hinshaw JE, Schmid SL. 1995. Dynamin self-assembles into rings suggesting a mechanism for coated vesicle budding. Nature 374: 190-192.

Honda A, Al-Awar OS, Hay JC, Donaldson JG. 2005. Targeting of Arf- 1 to the early Golgi by membrin, an ERGolgi SNARE. J Cell Biol 168: 1039-1051.

Hosobuchi M, Kreis T, Schekman R. 1992. SEC21 is a gene required for ER to Golgi protein transport that encodes a subunit of a yeast coatomer. Nature 360: 603-605.

Jin L, Pahuja KB, Wickliffe KE, Gorur A, Baumgartel C, Schekman R, Rape M. 2012. Ubiquitin-dependent regulation of COPII coat size and function. Nature 482: 495-500.

Kamena F, Spang A. 2004. Tip20p prohibits back-fusion of COPII vesicles with the endoplasmic reticulum. Science 304: $286-289$.

Kamena F, Diefenbacher M, Kilchert C, Schwarz H, Spang A. 2008. Yptlp is essential for retrograde Golgi-ER transport and for Golgi maintenance in S. cerevisiae. J Cell Sci 121: $1293-1302$.

Kartberg F, Asp L, Dejgaard SY, Smedh M, FernandezRodriguez J, Nilsson T, Presley JF. 2010. ARFGAP2 and ARFGAP3 are essential for COPI coat assembly on the Golgi membrane of living cells. J Biol Chem 285: 36709_ 36720. 
Kondylis V, Rabouille C. 2003. A novel role for dp115 in the organization of tER sites in Drosophila. J Cell Biol 162: $185-198$.

Kondylis V, Tang Y, Fuchs F, Boutros M, Rabouille C. 2011. Identification of ER proteins involved in the functional organisation of the early secretory pathway in Drosophila cells by a targeted RNAi screen. PLoS ONE 6: e17173.

Lanoix J, Ouwendijk J, Lin CC, Stark A, Love HD, Ostermann J, Nilsson T. 1999. GTP hydrolysis by arf-1 mediates sorting and concentration of Golgi resident enzymes into functional COP I vesicles. Embo $J$ 18: 4935-4948.

Lanoix J, Ouwendijk J, Stark A, Szafer E, Cassel D, Dejgaard K, Weiss M, Nilsson T. 2001. Sorting of Golgi resident proteins into different subpopulations of COPI vesicles: A role for ArfGAP1. J Cell Biol 155: 1199-1212.

Lee C, Goldberg J. 2010. Structure of coatomer cage proteins and the relationship among COPI, COPII, and clathrin vesicle coats. Cell 142: 123-132.

Lee MC, Orci L, Hamamoto S, Futai E, Ravazzola M, Schekman R. 2005a. Sarlp N-terminal helix initiates membrane curvature and completes the fission of a COPII vesicle. Cell 122: 605-617.

Lee SY, Yang JS, Hong W, Premont RT, Hsu VW. 2005b. ARFGAP1 plays a central role in coupling COPI cargo sorting with vesicle formation. J Cell Biol 168: 281-290.

Levi SK, Bhattacharyya D, Strack RL, Austin 2nd JR, Glick BS. 2010. The yeast GRASP Grh1 colocalizes with COPII and is dispensable for organizing the secretory pathway. Traffic 11: 1168-1179.

Lewis MJ, Sweet DJ, Pelham HR. 1990. The ERD2 gene determines the specificity of the luminal ER protein retention system. Cell 61: 1359-1363.

Lewis SM, Poon PP, Singer RA, Johnston GC, Spang A. 2004. The ArfGAP Glo3 is required for the generation of COPI vesicles. Mol Biol Cell 15: 4064-4072.

Lord C, Bhandari D, Menon S, Ghassemian M, Nycz D, Hay J, Ghosh P, Ferro-Novick S. 2011. Sequential interactions with Sec23 control the direction of vesicle traffic. Nature 473: 181-186.

Majoul IV, Bastiaens PI, Soling HD. 1996. Transport of an external Lys-Asp-Glu-Leu (KDEL) protein from the plasma membrane to the endoplasmic reticulum: Studies with cholera toxin in Vero cells. J Cell Biol 133: 777-789.

Majoul I, Sohn K, Wieland FT, Pepperkok R, Pizza M, Hillemann J, Soling HD. 1998. KDEL receptor (Erd2p)mediated retrograde transport of the cholera toxin $\mathrm{A}$ subunit from the Golgi involves COPI, p23, and the COOH terminus of Erd2p. J Cell Biol 143: 601-612.

Malkus P, Graham LA, Stevens TH, Schekman R. 2004. Role of Vma21p in assembly and transport of the yeast vacuolar ATPase. Mol Biol Cell 15: 5075-5091.

Meiringer CT, Rethmeier R, Auffarth K, Wilson J, Perz A, Barlowe C, Schmitt HD, Ungermann C. 2011. The Dsl1 protein tethering complex is a resident endoplasmic reticulum complex, which interacts with five soluble NSF (N-ethylmaleimide-sensitive factor) attachment protein receptors (SNAREs): Implications for fusion and fusion regulation. J Biol Chem 286: 25039-25046.

Oka T, Nakano A. 1994. Inhibition of GTP hydrolysis by Sar $1 p$ causes accumulation of vesicles that are a function- al intermediate of the ER-to-Golgi transport in yeast. J Cell Biol 124: 425-434.

Parlati F, Varlamov O, Paz K, McNew JA, Hurtado D, Sollner TH, Rothman JE. 2002. Distinct SNARE complexes mediating membrane fusion in Golgi transport based on combinatorial specificity. Proc Natl Acad Sci 99: 5424-5429.

Peyroche A, Paris S, Jackson CL. 1996. Nucleotide exchange on ARF mediated by yeast Geal protein. Nature 384: 479-481.

Peyroche A, Courbeyrette R, Rambourg A, Jackson CL. 2001. The ARF exchange factors Gealp and Gea2p regulate Golgi structure and function in yeast. J Cell Sci 114: 2241-2253.

Poon PP, Cassel D, Spang A, Rotman M, Pick E, Singer RA, Johnston GC. 1999. Retrograde transport from the yeast Golgi is mediated by two ARF GAP proteins with overlapping function. $E M B O J$ 18: 555-564.

Rein U, Andag U, Duden R, Schmitt HD, Spang A. 2002. ARF-GAP-mediated interaction between the ER-Golgi v-SNAREs and the COPI coat. J Cell Biol 157: 395-404.

Ren Y, Yip CK, Tripathi A, Huie D, Jeffrey PD, Walz T, Hughson FM. 2009. A structure-based mechanism for vesicle capture by the multisubunit tethering complex Dsl1. Cell 139: 1119-1129.

Robinson MS, Kreis TE. 1992. Recruitment of coat proteins onto Golgi membranes in intact and permeabilized cells: Effects of brefeldin A and G protein activators. Cell 69: $129-138$.

Rossanese OW, Soderholm J, Bevis BJ, Sears IB, O’Connor J, Williamson EK, Glick BS. 1999. Golgi structure correlates with transitional endoplasmic reticulum organization in Pichia pastoris and Saccharomyces cerevisiae. J Cell Biol 145: 69-81.

Sato M, Vardy L, Angel Garcia M, Koonrugsa N, Toda T. 2004. Interdependency of fission yeast Alp14/TOG and coiled coil protein Alp7 in microtubule localization and bipolar spindle formation. Mol Biol Cell 15: 1609-1622.

Schekman R, Orci L. 1996. Coat proteins and vesicle budding. Science 271: 1526-1533.

Schindler C, Spang A. 2007. Interaction of SNAREs with ArfGAPs precedes recruitment of Sec18p/NSE. Mol Biol Cell 18: 2852-2863.

Schindler C, Rodriguez F, Poon PP, Singer RA, Johnston GC, Spang A. 2009. The GAP domain and the SNARE, coatomer and cargo interaction region of the ArfGAP2/3 Glo3 are sufficient for Glo3 function. Traffic 10: 13621375.

Schweizer A, Fransen JA, Matter K, Kreis TE, Ginsel L, Hauri HP. 1990. Identification of an intermediate compartment involved in protein transport from endoplasmic reticulum to Golgi apparatus. Eur J Cell Biol 53: 185-196.

Semenza JC, Hardwick KG, Dean N, Pelham HR. 1990. $\mathrm{ERD} 2$, a yeast gene required for the receptor-mediated retrieval of luminal ER proteins from the secretory pathway. Cell 61: 1349-1357.

Shiba K, Kageyama H, Takenoya F, Shioda S. 2010. Galaninlike peptide and the regulation of feeding behavior and energy metabolism. FEBS J 277: 5006-5013. 
A. Spang

Smith RD, Willett R, Kudlyk T, Pokrovskaya I, Paton AW, Paton JC, Lupashin VV. 2009. The COG complex, Rab6 and COPI define a novel Golgi retrograde trafficking pathway that is exploited by SubAB toxin. Traffic 10: $1502-1517$.

Spang A. 2008. The life cycle of a transport vesicle. Cell Mol Life Sci 65: 2781-2789.

Spang A. 2009. On vesicle formation and tethering in the ER-Golgi shuttle. Curr Opin Cell Biol 21: 531-536.

Spang A. 2012. The DSL1 complex: The smallest but not the least CATCHR. Traffic 13: 908-913.

Spang A, Schekman R. 1998. Reconstitution of retrograde transport from the Golgi to the ER in vitro. J Cell Biol 143: 589-599.

Spang A, Matsuoka K, Hamamoto S, Schekman R, Orci L. 1998. Coatomer, Arflp, and nucleotide are required to bud coat protein complex I-coated vesicles from large synthetic liposomes. Proc Natl Acad Sci 95: 11199_ 11204.

Spang A, Herrmann JM, Hamamoto S, Schekman R. 2001. The ADP ribosylation factor-nucleotide exchange factors Gealp and Gea2p have overlapping, but not redundant functions in retrograde transport from the Golgi to the endoplasmic reticulum. Mol Biol Cell 12: 1035-1045.

Springer S, Schekman R. 1998. Nucleation of COPII vesicular coat complex by endoplasmic reticulum to Golgi vesicle SNAREs. Science 281: 698-700.

Springer S, Spang A, Schekman R. 1999. A primer on vesicle budding. Cell 97: 145-148.

Stagg SM, LaPointe P, Razvi A, Gurkan C, Potter CS, Carragher B, Balch WE. 2008. Structural basis for cargo regulation of COPII coat assembly. Cell 134: 474-484.

Storrie B, Micaroni M, Morgan GP, Jones N, Kamykowski JA, Wilkins N, Pan TH, Marsh BJ. 2012. Electron tomography reveals Rab6 is essential to the trafficking of trans-Golgi clathrin and COPI-coated vesicles and the maintenance of Golgi cisternal number. Traffic 13: $727-744$.

Takei K, McPherson PS, Schmid SL, De Camilli P. 1995. Tubular membrane invaginations coated by dynamin rings are induced by GTP-gamma $\mathrm{S}$ in nerve terminals. Nature 374: 186-190.

Tanigawa G, Orci L, Amherdt M, Ravazzola M, Helms JB, Rothman JE. 1993. Hydrolysis of bound GTP by ARF protein triggers uncoating of Golgi-derived COP-coated vesicles. J Cell Biol 123: 1365-1371.

Todorow Z, Spang A, Carmack E, Yates J, Schekman R. 2000. Active recycling of yeast Golgi mannosyltransferase complexes through the endoplasmic reticulum. Proc Natl Acad Sci 97: 13643-13648.

Tripathi A, Ren Y, Jeffrey PD, Hughson FM. 2009. Structural characterization of Tip20p and Dsllp, subunits of the
Dsllp vesicle tethering complex. Nat Struct Mol Biol 16: 114-123.

Valkova C, Albrizio M, Roder IV, Schwake M, Betto R, Rudolf R, Kaether C. 2011. Sorting receptor Rerl controls surface expression of muscle acetylcholine receptors by ER retention of unassembled alpha-subunits. Proc Natl Acad Sci 108: 621-625.

van der Bliek AM, Redelmeier TE, Damke H, Tisdale EJ, Meyerowitz EM, Schmid SL. 1993. Mutations in human dynamin block an intermediate stage in coated vesicle formation. J Cell Biol 122: 553-563.

Vanrheenen SM, Reilly BA, Chamberlain SJ, Waters MG. 2001. Dsl1p, an essential protein required for membrane traffic at the endoplasmic reticulum/Golgi interface in yeast. Traffic 2: $212-231$.

Waters MG, Serafini T, Rothman JE. 1991. "Coatomer": A cytosolic protein complex containing subunits of nonclathrin-coated Golgi transport vesicles. Nature 349: $248-251$.

Weimer C, Beck R, Eckert P, Reckmann I, Moelleken J, Brugger B, Wieland F. 2008. Differential roles of ArfGAP1, ArfGAP2, and ArfGAP3 in COPI trafficking. $J$ Cell Biol 183: 725-735.

Whitney JA, Gomez M, Sheff D, Kreis TE, Mellman I. 1995. Cytoplasmic coat proteins involved in endosome function. Cell 83: 703-713.

Witte K, Schuh AL, Hegermann J, Sarkeshik A, Mayers JR, Schwarze K, Yates JR 3rd, Eimer S, Audhya A. 2011. TFG1 function in protein secretion and oncogenesis. Nat Cell Biol 13: 550-558.

Yahara N, Sato K, Nakano A. 2006. The Arf1p GTPase-activating protein Glo3p executes its regulatory function through a conserved repeat motif at its C-terminus. $J$ Cell Sci 119: 2604-2612.

Yang JS, Lee SY, Gao M, Bourgoin S, Randazzo PA, Premont RT, Hsu VW. 2002. ARFGAP1 promotes the formation of COPI vesicles, suggesting function as a component of the coat. J Cell Biol 159: 69-78.

Yu X, Breitman M, Goldberg J. 2012. A structure-based mechanism for Arf1-dependent recruitment of coatomer to membranes. Cell 148: 530-542.

Zhao X, Claude A, Chun J, Shields DJ, Presley JF, Melancon P. 2006. GBF1, a cis-Golgi and VTCs-localized ARF-GEF, is implicated in ER-to-Golgi protein traffic. J Cell Sci 119: 3743-3753.

Zink S, Wenzel D, Wurm CA, Schmitt HD. 2009. A link between ER tethering and COP-I vesicle uncoating. Dev Cell 17: 403-416.

Zong M, Satoh A, Yu MK, Siu KY, Ng WY, Chan HC, Tanner JA, Yu S. 2012. TRAPPC9 mediates the interaction between p150 and COPII vesicles at the target membrane. PLoS ONE 7: e29995. 


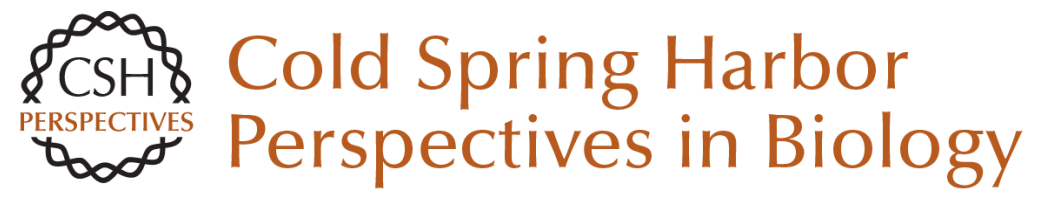

\title{
Retrograde Traffic from the Golgi to the Endoplasmic Reticulum
}

\author{
Anne Spang
}

Cold Spring Harb Perspect Biol 2013; doi: 10.1101/cshperspect.a013391

Subject Collection The Endoplasmic Reticulum

Sorting and Export of Proteins at the Endoplasmic Reticulum

Ishier Raote, Sonashree Saxena and Vivek Malhotra

Endoplasmic Reticulum Membrane Contact Sites, Lipid Transport, and Neurodegeneration Andrés Guillén-Samander and Pietro De Camilli

AMPylation and Endoplasmic Reticulum Protein Folding Homeostasis

Luke A. Perera and David Ron

The Endoplasmic Reticulum and the Fidelity of Nascent Protein Localization

Michael J. McKenna and Sichen Shao

Endoplasmic Reticulum Architecture and Inter-Organelle Communication in Metabolic Health and Disease

Ana Paula Arruda and Günes Parlakgül

Regulation and Functions of the ER-Associated

Nrf1 Transcription Factor

Gary Ruvkun and Nicolas Lehrbach

Mechanism of Protein Translocation by the Sec61

Translocon Complex

Samuel Itskanov and Eunyong Park

Evolutionary Aspects of the Unfolded Protein

Response

Kazutoshi Mori
Glycerolipid Synthesis and Lipid Droplet

Formation in the Endoplasmic Reticulum

Robert V. Farese, Jr. and Tobias C. Walther

The Biogenesis of Multipass Membrane Proteins Luka Smalinskaite and Ramanujan S. Hegde

A TAle of Two Pathways: Tail-Anchored Protein Insertion at the Endoplasmic Reticulum Alina Guna, Masami Hazu, Giovani Pinton Tomaleri, et al.

Cholesterol Transport to the Endoplasmic

Reticulum John P. Kennelly and Peter Tontonoz

The Role of the Rhomboid Superfamily in ER

Protein Quality Control: From Mechanisms and

Functions to Diseases

Satarupa Bhaduri, Nicola A. Scott and Sonya E. Neal

ER-Phagy: Quality and Quantity Control of the

Endoplasmic Reticulum by Autophagy Haruka Chino and Noboru Mizushima

Structure and Function of the Nuclear Pore Complex

Stefan Petrovic, George W. Mobbs, Christopher J. Bley, et al.

Post-Translational Regulation of HMG CoA

Reductase

Youngah Jo and Russell A. DeBose-Boyd

For additional articles in this collection, see http://cshperspectives.cshlp.org/cgi/collection/

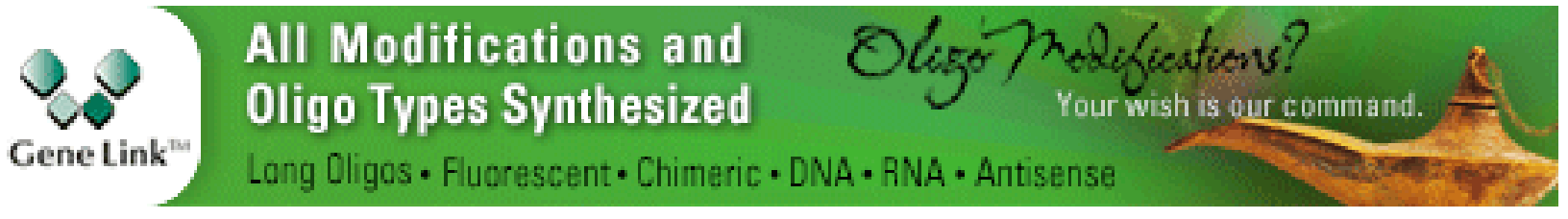


For additional articles in this collection, see http://cshperspectives.cshlp.org/cgi/collection/

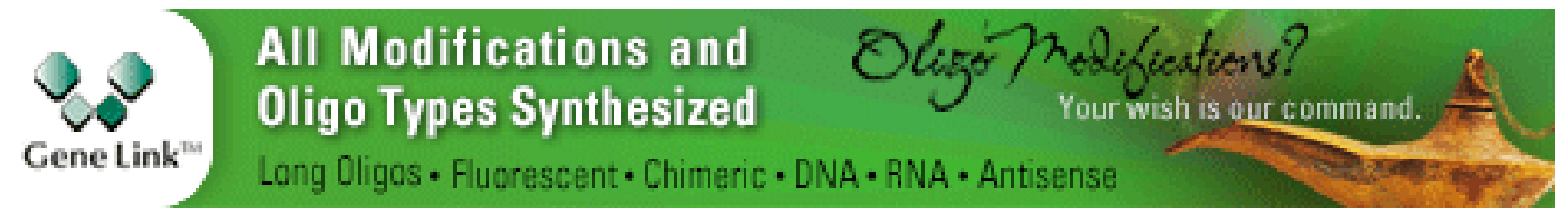

Copyright @ 2013 Cold Spring Harbor Laboratory Press; all rights reserved 